\title{
Orta Anadolu koşullarında Ceviz antraknozu etmeni Gnomonia leptostyla (Fr.) Ces et de Not.'nın mücadelesine yönelik biyolojik parametreler ${ }^{1}$
}

\author{
$\underline{\text { Servet UZUNOK }}^{2}$
}

\author{
Illker KURBETLi $\dot{i}^{3}$
}

\section{ABSTRACT \\ Biological parameters to control of walnut anthracnose agent Gnomonia leptostyla (Fr.) Ces et de Not. in Central Anatolian conditions}

The main disease of walnut is anthracnose caused by Gnomonia leptostyla (Fr.) Ces et de Not. The disease is very destructive when the conditions are favorable for disease growth. This study was conducted in Oğuzlar district of Çorum province, one of the largest walnut growing regions of Turkey from 2005 to 2011. Biological parameters (phenological stage of walnut, the dates of perithecia maturing and infection, climate etc.) to control the disease were obtained during the study. Walnut trees were damaged due to the late spring frost in 2006 and hail in 2007, and their effects continued in 2008. During these years, yield was low in trees and the trees turned to vegetative growth. According to years, perithecia matured from March 21 to April 6; primer infections occurred from April 17 to May 8; seconder infections happened from May 15 to June 12. These stages were beginning to burst of buds, and cat ear stage; the stage when the leaves passed half the size; the stage when the fruits were big hazelnut, respectively.

Keywords: Walnut, anthracnose, Gnomonia leptostyla

\section{$\ddot{O Z Z}$}

Cevizin ana hastalığı Gnomonia leptostyla (Fr.) Ces et de Not.'nın neden olduğu antraknozdur. Hastalık için uygun koşullar oluştuğunda etmen oldukça tahripkârdır. Bu çalışma, ülkemizin önemli ceviz üretim bölgelerinden biri olan Çorum ilinin Oğuzlar

$1 \mathrm{Bu}$ makale TAGEM tarafindan desteklenen TAGEM-BS-05/15-01/01-02-01 numaralı "Ceviz Bahçelerinde Ceviz Antraknozu [Gnomonia leptostyla (Fr.) Ces et de Not.] ve Elma İçkurdu [(Cydia pomonella L.) (Lep.: Tortricidae)]'nun Mücadelesinde Tahmin Uyarı Modelinin Oluşturulmasına Yönelik Çalışmalar" isimli projenin bir bölümüdür.

2 Zirai Mücadele Merkez Araştırma Enstitüsü Müdürlügü̈, 06172, Yenimahalle, ANKARA

3 Batı Akdeniz Tarımsal Araştırma Enstitüsü Müdürlüğü, ANTALYA

Sorumlu yazar (Corresponding author) e-mail: servet.uzunok@tarim.gov.tr

Alınış (Received): 13.04.2017, Kabul ediliş (Accepted): 25.09.2017 
Orta Anadolu koşullarında ceviz antraknozu etmeni Gnomonia leptostyla (Fr.) Ces et de Not.'nın mücadelesine yönelik biyolojik parametreler

ilçesindeki bir ceviz bahçesinde, 2005-2011 yılları arasında yürütülmüștür. Çalışma süresince hastalığın mücadelesine yönelik biyolojik parametreler (cevizin fenolojik dönemi, peritesyum olgunlaşma ve enfeksiyon tarihleri, iklimsel veriler gibi) elde edilmiş̧ir. Çalışmaların yapıldığı 2006 yılında ilkbahar geç donlarından, 2007 yılında ise dolu zararından kaynaklanan olumsuzluklar 2008 yılında da etkisini sürdürmüștür. Bu dönemde ağaçlarda meyve tutumu çok az olmuş ve ağaçlar vejetatif büyümeye yönelmiştir. Yıllara göre değişmekle birlikte peritesyum olgunlaşması 21 Mart-6 Nisan; primer enfeksiyonlar 17 Nisan-8 Mayıs; sekonder enfeksiyonlar ise 15 Mayıs-12 Haziran tarihleri arasında gerçekleşmiştir. Bu dönemler sırasıyla, tomurcukların patlamaya başlaması ve kedi kulağı, yapraklardaki yaprakçıkların yarı büyüklüğünü geçtiği, meyvelerin iri findık büyüklüğünde olduğu fenolojik dönemlere karşıllık gelmiştir.

Anahtar kelimeler: Ceviz, antraknoz, Gnomonia leptostyla

\section{GİRis}

FAO verilerine göre 2014 y1lında dünyada yaklaşık 995 bin hektar alanda, 3 milyon 462 bin ton ceviz üretilmiştir (Anonymous 2014). Dünya üretiminde ilk sırayı yaklaşık 1 milyon 600 bin ton ile Çin alırken, bunu 518 bin ton ile ABD, 445 bin ton ile İran ve 180 bin ton ile Türkiye izlemektedir. Dünya ceviz verim ortalaması ise dekar bazında 240 ila $300 \mathrm{~kg}$ arasında değişim göstermektedir. Türkiye'de ceviz üretimi istikrarlı bir seyir izlerken, verilen desteklerin de etkisiyle son 10 yılda ceviz üretimi \%64.4'lük artışla, 2014 yılında 180 bin 807 tona ulaşmıştır.

Avrupa'da ilk kez 1815 yılında rapor edilen Ceviz antraknozu hastalığı, ceviz yetiştiriciliğinin yapıldığ 1 hemen her yerde yaygın olarak görülmekte ve ciddi kayıplara yol açabilmektedir (Belisario 2002). Hastalığın Avrupa dıșında Amerika Birleşik Devletleri, Güney Afrika ve Asya'da varlığı bildirilmiștir (Anonymous 2013, Karov et al. 2014). Hastalık etmeni Avrupa ülkelerinden Hirvatistan, İtalya, Makedonya, Surbistan, Slovakya, Slovenya ve Yunanistan'da tanımlanmıştır (Apostolides 1952, Balaž et al. 1991, Solar and Štampar 2005, Juhasova et al. 2006, Barić et al. 2008, Belisario et al. 2008, Karov et al. 2014). Ceviz antraknozu hastalığının ülkemizde varlığını ilk kez ortaya koyan Bremer (1954)'e göre hastalık Türkiye'nin her tarafında yaygın olarak bulunmakta ve rutubetli yerlerde zararı daha fazla olmaktadır. Geçmişte hastalığın Ankara, Antalya, Bolu, Gümüşhane, İzmir, Malatya, Muğla ve Kütahya'da zarar yaptığı tespit edilmiş (Bremer 1954, Karel 1958), ayrıca hastalığa Artvin, Eskișehir ve Konya illeri ile Karadeniz sahilinde yaygın olarak rastlandığı bildirilmiştir (Karaca 1960). Buna ek olarak Karaca (1960) yapmış olduğu çalışma sonucunda, bu hastalıkta primer enfeksiyonların çok önemli olduğu, salgın riskinin nisan ve mayıs aylarındaki yağışlara bağlı olduğu ve bu aylarda aylık yağıș miktarı 100 mm'ye ulaşmadıkça bir salgın beklenmemesi gerektiği kanaatine varmıştır. Son yıllarda yapılmış olan nadir çalışmalardan biri ise hastalığın Erzincan, Erzurum, Gümüşhane, Iğdır ve Kars illerinde yaygın olarak bulunduğunu ortaya koymaktadır (Gökçe ve ark. 2011). 
Ceviz antraknozu hastalığ saprofitik ve parazitik olmak üzere 2 devresi vardır. Saprofitik dönem sonbaharda yere dökülen ölü yapraklarda başlar, ilkbaharda peritesyumun olgunlaşmasına kadar sürer. Parazitik dönem ise, fungusun ilkbahardan itibaren canlı dokularda sürdürdüğü yaşamını kapsamaktadır. Etmenin miselyumları bölmelidir, önceleri renksiz adeta şeffaf, daha sonraları koyulaşarak, kirli beyaz, krem rengini alır. Epidermis ve kütiküla arasında gelişerek, aservulus oluşturur. Aservuluslar olgunlaştıklarında, yağmur sıçratmasıyla konidiler etrafa yayılırlar. Konidiler renksiz şeffaf, ortadan tek bölmeli, hilal şeklinde, bölme ortadan ziyade bir uca daha yakındır. Ceviz antraknozu hastalığı ile zamanında mücadeleye başlanmadığı durumlarda etmen ciddi ürün kayıplarına ve ağaç ölümlerine neden olmaktadır (Klebahn 1907, Berry 1961).

Bitki hastalıklarıyla mücadele edebilmek için öncelikle patojenin mevcut ekolojik koşullarda biyolojisinin bilinmesi gerekmektedir. Ceviz antraknozu hastalık etmeninin biyolojisine ilişkin ülkemizdeki tek çalışma Karaca (1960) tarafından 1955-1959 yılları arasında Artvin ili ve ilçelerinde yürütülmüş, söz konusu çalışmada Artvin'den getirtilen enfekteli yapraklar Ankara koşullarında da değerlendirilmiştir. Orta Anadolu Bölgesi'nde konuya ilişkin bahçe koşullarında yapılmış kapsamlı bir çalışma bulunmamaktadır. Üstelik yapılan o çalışmadan itibaren yarım asır geçmiş, gerek dünyada gerekse ülkemizde iklimsel ve ekolojik değişiklikler kaçınılmaz olmuştur. $\mathrm{Bu}$ çalışmanın amacı, cevizin en önemli hastalıklarından biri olan ve mücadele edilmediğinde ülkemizde de ciddi ekonomik kayıplara yol açabilen Ceviz antraknozu etmeni G. leptostyla'nın mücadelesine yönelik Orta Anadolu koşullarındaki önemli biyolojik parametreleri belirlemektir. Nitekim çalışma yapılan yer Orta Anadolu Bölgesi'nin en önemli ceviz üretim alanlarından birisidir. Çorum ili Oğuzlar ilçesinde 2013 yılında gerçekleştirilen 'Oğuzlar77 Ceviz Çeşidi Envanter Çalışması'na göre, 10.805 da alanda toplam 153.977 adet ceviz ağacı bulunmakta ve yaklaşı $1.500 \mathrm{~kg}$ ceviz üretilmektedir (Anonim 2013). Bu veriler, çalışma alanı olarak Oğuzlar ilçesinin seçilmesinin doğru bir karar olduğunu ortaya koymaktadır.

\section{MATERYAL VE METOT}

\section{Materyal}

Çalışmanın materyalini, Çorum ili Oğuzlar ilçesindeki ceviz bahçesi, tahmin ve uyarı sisteminde kullanılan elektronik alet ve malzemeler, vazelinli lam tuzakları ve sportrap oluşturmuştur. Bu çalışmada kullanılan fenolojik, biyolojik ve iklimsel veriler çalışmanın yapıldığı bahçeden kayıt altına alınarak değerlendirmeye tabi tutulmuştur. 
Orta Anadolu koşullarında ceviz antraknozu etmeni Gnomonia leptostyla (Fr.) Ces et de Not.'nın mücadelesine yönelik biyolojik parametreler

\section{Metot}

\section{Peritesyum olgunlaşmasının saptanması}

Sonbahardan itibaren araştırmanın yapıldı̆̆ı bahçelerden, hastalıklı ağaçların altlarından toplanan enfekteli yapraklar, üst kısmı kafes tel ile kapatılmış kasalara konulmuş ve tamamen doğal koşullarda bırakılmıștır. Bu yapraklar mart ayı itibariyle mikroskopta incelenerek peritesyum olgunlaşması 2 günde bir takip edilmiştir. İlk askosporun görüldügüü tarih peritesyum olgunlaşma tarihi olarak kabul edilmiştir.

\section{Doğada askospor uçuşunun izlenmesi}

Sportraptan haftalık kayıtlar alınmıştır. Bununla birlikte vazelinli yüzeyleri yapraklara gelecek şekilde lam tuzakları dallara asılarak askospor ve konidi uçuşları tespit edilmiştir. Doğada askospor ve konidilerin izlenmesi vejetasyon dönemi boyunca yapılmıştır.

\section{Enfeksiyon periyotlarının belirlenmesi}

Önceden araştırma bahçesine yerleştirilmiş olan bilgisayarlı iklim veri cihazından günlük sıcaklık, nem ve yaprak 1slaklık süresi değerleri alınarak fungusun enfeksiyon periyotları belirlenmeye çalışılmışıtır. Ayrıca ceviz bahçesinde tahmin ve uyarı cihazının don verileri takip edilerek kayıt altına alınmıştır.

\section{SONUÇLAR}

Her bir yıl için ayrı ayrı tablo değerlerine genel baktığımızda doğa ortamında elde edilen veriler Gnomonia leptostyla'nın peritesyum olgunlaşması, primer ve sekonder enfeksiyonların farklı iklim verileri ve tarihlerinde oluşum gösterdiği görülmektedir (Çizelge 1, 2, 3). Özellikle 2006-2007 döneminde meydana gelen olumsuz doğa olayları, 2007 ve 2008 yıllarına ait verilere açıkça yansımıştır. 2006 yılında ilkbahar geç donları ceviz ağaçlarının sürgün, meyve ve yapraklarında önemli zarara yol açmıştır. 2007 yılındaki dolu zararı da önceki yılın don zararı gibi oldukça yıkıcı olmuştur. Ağaçlar sonraki yıllarda zararı tolere edebilmek için vejetatif büyümeye yönelmişlerdir. Yapımı biten ve 2009 yılında işletmeye alınan Obruk Barajı nem değerlerini artırmıştır. Yağışlar 2010 ve 2011 yıllarının nisan, mayıs ve haziran aylarının 1/3'ünde görülmüş, sonraki dönemler sıcak ve kurak geçmiştir. 
Çizelge 1. Tüm yıllara göre peritesyumların olgunlaşmaya başladığı tarihler

\begin{tabular}{|c|c|c|}
\hline Tarih & İklimsel veriler & evizin fenolojisi \\
\hline 29.03 .2005 & Sicaklık: $11.62{ }^{\circ} \mathrm{C}$ Yaprak 1slaklığı süresi: 21,24 saat & \multirow{7}{*}{$\begin{array}{l}\text { Tomurcukların } \\
\text { patlamaya } \\
\text { başlaması ve kedi } \\
\text { kulağı }\end{array}$} \\
\hline 30.03 .2006 & Sicaklık: $14.3{ }^{\circ} \mathrm{C}$ Yaprak 1slaklığı süresi: 3,9 saat & \\
\hline 06.04 .2007 & Sicaklık: $9.19^{\circ} \mathrm{C}$ Yaprak 1slaklığı süresi: 9 saat & \\
\hline 21.03 .2008 & Sicaklık: $11.62{ }^{\circ} \mathrm{C}$ Yaprak 1slaklığı süresi: 21,24 saat & \\
\hline 03.04 .2009 & Sicaklık: $10.12{ }^{\circ} \mathrm{C}$ Yaprak 1slaklığı süresi: 7,12 saat & \\
\hline 29.03 .2010 & Sicaklık: $9.9^{\circ} \mathrm{C}$ Yaprak sslaklığı süresi: 10,06 saat & \\
\hline 06.04 .2011 & Sicaklık: $10.01{ }^{\circ} \mathrm{C}$ Yaprak 1slaklığ süresi: 6,40 saat & \\
\hline
\end{tabular}

Hastalığın yıllara göre fenolojik dönemlerinden peritesyumların olgunlaşmaya başladığı tarihlerin yer aldığı Çizelge 1 incelendiğinde 2005 ile 2010, 2007 ile 2011 yıllarında aynı tarihlerde gerçekleştiği görülmektedir. 2006, 2008 ve 2009 yıllarında peritesyum olgunlaşması farklı tarihlerde başlamıştır. Yıllara göre 7 günlük tarihler arasında sapma görülmektedir. İklimsel verilere baktığımızda sıcaklık değerlerinin yıllara göre yaklaşık aynı değerlerde olduğu ancak yaprak 1slaklık sürelerinin farklı olduğu görülmektedir.

Çizelge 2. Tüm yıllara göre primer enfeksiyon tarihleri

\begin{tabular}{|c|c|c|}
\hline Tarih & İklimsel veriler & Cevizin fenolojisi \\
\hline 23.04 .2005 & Sicaklık: $12.91{ }^{\circ} \mathrm{C}$ Yaprak sslaklığı süresi:18,5 saat & \multirow{7}{*}{$\begin{array}{l}\text { Yapraklardaki } \\
\text { yaprakçıkların yarı } \\
\text { büyüklügünü } \\
\text { geçtiği dönem }\end{array}$} \\
\hline 08.05 .2006 & Sıcaklık: $12.15^{\circ} \mathrm{C}$ Yaprak 1slaklığı süresi:13 saat & \\
\hline 29.04 .2007 & Sicaklık: $10.05^{\circ} \mathrm{C}$ Yaprak 1slaklı̆ğ süresi:17 saat & \\
\hline 17.04 .2008 & Sicaklık: $12.34{ }^{\circ} \mathrm{C}$ Yaprak 1slaklığ süresi:10,12 saat & \\
\hline 05.05 .2009 & Sicaklık: $10.05^{\circ} \mathrm{C}$ Yaprak 1slaklığı süresi:17,24 saat & \\
\hline 18.04 .2010 & Sicaklık: $10.05^{\circ} \mathrm{C}$ Yaprak 1slaklığı süresi:18,04 saat & \\
\hline 05.05 .2011 & Sicaklık: $13.26{ }^{\circ} \mathrm{C}$ Yaprak 1slaklığ 1 süresi:14,10 saat & \\
\hline
\end{tabular}

Çizelge 2 incelendiğinde primer enfeksiyon tarihlerinin 2009 ve 2011 y1llarında aynı, diğer yıllarda ise farklı tarihlerde gerçekleştiği anlaşılmaktadır. Yine sıcaklık değerlerinin birbirine yakın, yaprak ıslaklık değerlerinin ise farklı değerlerde olduğu görülmektedir. Primer enfeksiyon tarihleri 17 Nisan ile 8 Mayıs tarihleri arasında dağglım göstermektedir.

Çizelge 3. Tüm yıllara göre sekonder enfeksiyon tarihleri

\begin{tabular}{|c|c|c|}
\hline Tarih & İklimsel veriler & Cevizin fenolojisi \\
\hline 01.06 .2005 & Sıcaklık: $16.36{ }^{\circ} \mathrm{C}$ Yaprak ıslaklığı süresi:19,2 saat & \multirow{7}{*}{$\begin{array}{l}\text { Meyvelerin iri } \\
\text { findık } \\
\text { büyüklüğünde } \\
\text { olduğu dönem }\end{array}$} \\
\hline 07.06 .2006 & Sicaklık: $19.27^{\circ} \mathrm{C}$ Yaprak ıslaklığı süresi: 4,24 saat & \\
\hline 12.06 .2007 & Sıcaklık: $16.73{ }^{\circ} \mathrm{C}$ Yaprak 1slaklığı süresi:10 saat & \\
\hline 16.05 .2008 & Sicaklık: $14.66^{\circ} \mathrm{C}$ Yaprak ıslaklığı süresi: 9,36 saat & \\
\hline 20.05 .2009 & Sicaklık: $19.27^{\circ} \mathrm{C}$ Yaprak ıslaklığı süresi: 2,48 saat & \\
\hline 15.05 .2010 & Sicaklık: $19.95^{\circ} \mathrm{C}$ Yaprak ıslaklığı süresi: 8,06 saat & \\
\hline 17.05 .2011 & Sicaklık: $18.58^{\circ} \mathrm{C}$ Yaprak ıslaklığı süresi: 9,00 saat & \\
\hline
\end{tabular}


Orta Anadolu koşullarında ceviz antraknozu etmeni Gnomonia leptostyla (Fr.) Ces et de Not.'nın mücadelesine yönelik biyolojik parametreler

Çizelge 3 incelendiğinde, sekonder enfeksiyon tarihlerinin yıllara göre farklı zamanlarda olduğu görülmektedir. Peritesyum olgunlaşması ve primer enfeksiyon tarihlerinde olduğu gibi sekonder enfeksiyonlarda da sicaklık değerleri birbirlerine yakın, yaprak 1slaklık süreleri ise farklılık arz etmiştir. Sekonder enfeksiyonlar, en erken 15 Mayıs, en geç 12 Haziranda oluşmuştur.

\section{TARTISSMA VE KANI}

Gnomonia leptostyla'nın peritesyum olgunlaşma tarihleri ile primer ve sekonder enfeksiyon tarihleri, etmenin neden olduğu ceviz antraknozu hastalığı ile mücadelede ilaçlamaların yapıldığı bitkinin fenolojik dönemleriyle paralellik göstermiştir. Etmenin biyolojik dönemleri ile bitkinin gelişim dönemleri paralel olmakla birlikte yıllar arasında tarihlerde farklılıklar görülmüştür. Peritesyumlar mart ayının sonu ile nisan ayının başlarında olgunlaşmaya başlamıştır. Bu dönem, bitkinin fenolojik olarak tomurcukların yeni patlamaya başladığı, yaprakların kedi kulağı olduğu dönemi kapsamaktadır. Bu dönemde sıcaklık ortalama $10.9{ }^{\circ} \mathrm{C}$ olarak gerçekleşmiş nemle birlikte yaprak 1slaklık süresinin en az 6 saati geçmesiyle askospor uçuşları meydana gelmiştir. İllinois Üniversitesinde 1987 yılında yapılan bir çalışmada, 7 ile $10{ }^{\circ} \mathrm{C}$ sıcaklıkta ve 4-6 saat yaprak islaklığ 1 süresinin geçmesiyle olgunlaşan peritesyumdan yoğun düzeyde askosporların doğaya salındığı bildirilmiştir (Pataky 1987). Bu çalışma ile tarafımızca elde edilen veriler arasında paralellik görülmektedir. Halbuki ülkemizde önceki yıllarda yapılan bir çalışmada peritesyumların Ankara'da 7 Nisan'da, Artvin (Çoruh)'de ise 15 Nisan'da olgunlaşmaya başladığı bildirilmiştir (Karaca 1960). Mevcut çalışmanın yapıldığı Çorum ilinin iklimsel olarak Ankara ile daha benzer olduğu düşünüldüğünde, veriler arasında yine de büyük bir farklılık olmadığ 1 görülmektedir. Üstelik aradan geçen 50 yıl içerisinde yaşanan iklim değişikliklerinin bitki hastalıkları üzerinde de potansiyel etkisi muhtemeldir.

Yapılan çalışmalarda primer enfeksiyon tarihlerinin, yapraktaki yaprakçıkların yarı büyüklüğünü aldığı fenolojik dönemde gerçekleştiği görülmektedir. Yalnızca 2006 yılında meydana gelen ilkbahar geç donları, ağaçlardaki yaprakların birçoğunda yanıklığa neden olduğu için askosporlar enfekte edecek çok az yaprak bulabilmişlerdir. Enfeksiyonlar yıllar itibariyle nisan ayının 2. yarısından mayıs ayının ilk haftası arasındaki tarihlerde gerçekleşmiştir. Sıcaklık yaklaşık $12{ }^{\circ} \mathrm{C}$, yaprak 1slaklık süresi ise ortalama 15 saati geçmiş ve $\% 68$ nem ile enfeksiyonlar oluşmuştur. Andrievskii and Rikhter (1976), $16-17{ }^{\circ} \mathrm{C}$ sıcaklık, \%65-70 üzerindeki nemin enfeksiyon için çok uygun olduğunu bildirmektedir. Elde edilen veriler bu çalışmadaki verilerle yakınlık arz etmektedir.

Sekonder enfeksiyonlar, ceviz ağacının fenolojik olarak meyvelerinin iri findık büyüklüğü döneminde enfeksiyona başlamaktadır. Yapılan çalışmalarda mayıs ayının 2. yarısı ile haziran ayının ilk $1 / 3$ 'lük diliminde enfeksiyon tarihleri oluşmuştur. Enfeksiyon dönemlerinde sicaklık değerleri ortalama $15{ }^{\circ} \mathrm{C}$ yaprak 
1slaklık süresi ise 9 saat olarak gerçekleşmiştir. İllinois Üniversitesindeki çalışmada sekonder enfeksiyonların, yaprak sslaklık süresinin 6 saati ve sıcaklığın $15{ }^{\circ} \mathrm{C}$ 'yi geçmesi ile optimum değerlerde gerçekleştiği bildirilmiştir (Pataky 1987). Her iki çalışma da birbirleriyle uyumluluk göstermektedir.

Yapılan çalışmalar sonucunda belirlenen cevizin fenolojik dönemleri ile hastalık etmeninin enfeksiyon dönemlerinin, mevcut bilinen ilaçlama zamanları ile paralellik gösterdiği görülmüştür. Peritesyum olgunlaşma döneminde yani ceviz bitkisinin fenolojik olarak tomurcukların patladığı ve yaprakların kedi kulağı olduğu dönemde birinci ilaçlama yapılmalıdır. Primer enfeksiyonlar için ceviz bitkisinin yapraklardaki yaprakçıkların yarı büyüklüğünü aldığı dönemde ikinci, sekonder enfeksiyonlar için ise meyvenin findık büyüklügünü aldığı dönemde üçüncü ilaçlama yapılmalıdır. Yağışlı geçen yerlerde kullanılan fungisitin etki süresi dikkate alınarak ve enfeksiyon koşulları devam ettiği takdirde dördüncü ve diğer ilaçlamalara devam edilmelidir. Bu hastalıkta primer enfeksiyonlar çok önemlidir. $\mathrm{Bu}$ nedenle kültürel önlem olarak primer enfeksiyon kaynağı olan sonbaharda yere dökülmüş enfekteli yaprakların toplanarak imha edilmesi hastalıkla mücadelede çok önemli bir yoldur (Karaca 1960, Anonim 2008). Bu sayede hem hastalık şiddeti muhtemelen çok düşük olacak hem de kimyasal mücadelenin başarı şansı artacaktır.

Çorum ili Oğuzlar ilçesindeki ceviz bahçesinde 7 yıllık çalışma süresince, 2006 yılında ilkbahar geç donları ve 2007 yılında dolu zararı yaşanmıştır. Bunun yanı sıra 2009 yılında çalışma yapılan ceviz bahçesine 3-4 km uzaklıkta yapılan Obruk barajının devreye girmesi ve buna bağlı olarak azda olsa nem değerlerinin artması çalışmayı etkileyen faktörler olarak sıralanabilir. Tüm bunlara karşın elde edilen sonuçlara bakıldığında tespit edilen fenolojik dönem, enfeksiyon tarihleri ve iklimsel verilerden yola çıkılarak ceviz bahçelerinde Ceviz antraknozu (Gnomonia leptostyla (Fr.) Ces et de Not.) hastalığ 1 ile mücadelede, ileride yapılacak çalışmalar için temel verilerin elde edildiği düşünülmektedir.

\section{KAYNAKLAR}

Andrievskii A. V. and Rikhter A. A. 1976. Selection of walnut plants resistant to Marssonina. Review of Plant Pathology, 56 (11), 1042.

Anonim 2008. Ceviz Antraknozu. Zirai Mücadele Teknik Talimatları, Sert Kabuklu Meyve Hastalıkları, Fungal Hastalıklar, Cilt 5, Sayfa 183-185. Tarım ve Köyişleri Bakanlığı, Tarımsal Araştırmalar Genel Müdürlüğü.

Anonim 2013. Oğuzlar77 Ceviz Çeşidi Envanter Çalışması, Mart 2013. Oğuzlar Ceviz Üreticileri Tarımsal Birliği. http://oka.org.tr/Documents/ Oguzlar\%2077\%20Cevizi\%20Envanter\%20\%C3\%87al\%C 4\%B1\%C5\%9Fmas\%C4\%B1.pdf (Erişim tarihi: 07.07.2017).

Anonymous 2013. $\mathrm{CAB}$ international distribution maps of plant diseases, 1986, October (Edition 3), pp Map 384. 
Orta Anadolu koşullarında ceviz antraknozu etmeni Gnomonia leptostyla (Fr.) Ces et de Not.'nın mücadelesine yönelik biyolojik parametreler

Anonymous 2014. Walnut production data of the world.
http://www.fao.org/faostat/en/\#data/QC (Erişim tarihi: 28.03.2017).

Apostolides C. A. 1952. Annales de l'Institut Phytopathologique Benaki, 6 (2): 62-78.

Balaž J., Korać M. and Cerović S. 1991. Osetljivost genotipova oraha prema Gnomonia leptostyla (Fr) Ces. de Not. prouzrokovaču lisne pegavosti. Jugoslovensko Voćarstvo, 25 (1-2): 91-94.

Barić L., Diminić D., Glavaš M. and Hrašovec B. 2008. Zdravstveno stanje drveca u gradu Pakracus posebnim osvrtom na bolesti I štetnike lišca. Radovi - Šumarski Institut Jastrebarsko, 43 (1): 59-70.

Belisario A. 2002. Anthracnose. In: Teviotdale, B. L., Michailides, T. J., Pscheidt, J. W. (eds). Compendium of Nut Crop Diseases in Temperate Zones, Part VI. Walnut Diseases, pp: 77-78. The American Phytopathological Society, St. Paul, Minnesota, USA.

Belisario A., Scotton M., Santori A. and Onofri S. 2008. Variability in the Italian population of Gnomonia leptostyla, homothalism and resistance of Juglans species to anthracnose. Forest Pathology, 38 (2): 129-145.

Berry F. H. 1961. Etiology and control of walnut anthracnose. Md. Agric. Exp. Stn. Bull., A-I $13.22 \mathrm{p}$.

Bremer H. 1954. Türkiye Fitopatolojisi. Cilt 3 Bahçe Kültürleri Hastalıkları, Çeviren: M. Özkan. Ziraat Vekaleti Neşriyat ve Haberleşme Müdürlüğü, Ankara İstiklal Matbaası, Sayı: 715.

Gökçe A. Y., Turak S., Albayrak S. ve Akbaș H. R. 2011. Doğu Anadolu bölgesinde meyve ağaçlarında sorun olan fungal etmenlerin tespiti. Bitki Koruma Bülteni, 51 (1): 33 44.

Juhasova G., Ivanova H. and Spisak J. 2006. Biology of fungus Gnomonia leptostyla in agroecological environments of Slovakia. Mikologiya Fitopatologiya, 40: 538-547.

Karaca İ. 1960. Gnomonıa Leptostyla (Fr.) Ces. et de Not. mantarlarının biyolojisi üzerinde bir etüd. Bitki Koruma Bülteni, 1 (3): 3-9.

Karel G. 1958. A preliminary iist of plant diseases in Turkey. Y1ld1z Matbaas1, Ankara, 44.

Karov I., Mitrev S., Kovacevik B., Stoyanova Z., Kostadinoska E. and Rodeva R. 2014. Gnomonıa Leptostyla (Fr.) Ces. Et De Not. causer of walnut anthracnose in the East Part of the Republic of Macedonia. Goce Delcev University, Faculty of Agriculture Yearbook, Vol. 12, pp. 119-128.

Klebahn H. 1907. Untersuchungen Oiber einige fungi imperfecti und die zugeh6rigen ascomycetenformen. IV. Marssonina juglandis (Lib.) Sacc. Z. Pflanzenkrankh. 17: 223-237.

Solar A. and Štampar F. 2005. Evaluation of some perspective walnut genotypes in Slovenia. Acta Horticulturae (ISHS), 705: 131-136.

Pataky N. 1987. Fungal leaf spots of black walnut. Department of Crop Sciences, University of Illinois at Urbana-Champaign. Report on Plant Disease, RPD no. 600. 